\title{
17 The integration of IT and teacher training: supporting teachers in their use of hardware and software tools in the school mathematics classroom
}

\author{
Philippe Clarou \\ IUFM, Grenoble \\ France
}

\begin{abstract}
While initial teacher training has a full agenda, the programmes in France have a particular concern for the need to support teachers in their use of powerful IT tools in the teaching of the subjects of the curriculum. In the case of mathematics the concern has included both the need for the provision of opportunities for the acquisition of skills for personal exploration of important concepts and relationships as well as, and potentially even more important, the participation in specifically designed classroom focused 'scenarios in use' which attempt to illustrate the potential learning outcomes from pupils' engagement with specific software tools.
\end{abstract}

\section{Keywords}

Teacher education, pedagogy, geometry, graphics/programmable calculators, learning materials.

\section{INTRODUCTION}

At the secondary level of teaching in France it might be questioned whether New Educational Technology (NET) in general, and the possibilities for using computers in class in particular, are exploited as much as the different equipment allows. Indeed there is still the problem of limited facilities in a certain number of establishments. However, secondary schools have at their disposal relatively upto-date equipment which is often reserved exclusively for the teaching of 
technology. In the grammar schools (lycées) there is almost always equipment used for computer aided experimentation (EXAO) in physical, natural and earth sciences. This is without counting the equipment used in the teaching of certain specialised subjects such as IT and administration. But whilst there are several rooms equipped to allow the use of software in other subjects, one often finds that the different possibilities are considerably under-exploited.

One might also ask whether the integrated use of NET by teachers on teaching practice corresponds to the expansion of what is available in educational establishments. In fact the teaching population reacts in very different ways: on the one hand there are some very enthusiastic teachers and on the other an enormous inertia. At this moment in time new interfaces permit software to be made available which one can rapidly master at the basic handling level. In the past students had to learn to communicate with the computer or to use a program. Today the computer facilitates learning. The problem, therefore, now rests entirely with the teacher. Teachers must be capable of using fully the immense possibilities, sometimes very newfangled, of the computer to contribute to the learning process in their disciplines and of using approaches which may be completely new. Also, the nature of learning itself can be affected.

\section{WHAT IS AT STAKE AT THE INTRODUCTORY LEVEL OF TRAINING.}

One might think that at the introductory level of training, and in particular at the level of IUFM (institut universitaire), there is a lot at stake with regard to the development of new educational technology and its effective use in the classroom. Several enquiries carried out in collaboration with the Department of New Technology and Education at the National Institute for Pedagogical Research (INRP) show simultaneously that more and more future teachers are users of software-tools when they enter IUFM, that they often have a certain amount of training (especially in the scientific disciplines) and that their expectations are important not only at the personal level but also as regards the use of this software as a teaching tool integrated with their discipline. A study of the different curricula of the IUFMs shows that training in the use of these new tools holds a significant place.

At the IUFM one also finds a great willingness to use IT on the part of the lecturers themselves, who rely on the students following their example: the assumption is that the future teachers will accordingly use the new tools which they will have used in training in the contexts in which they have used them. An analysis of the difficulties of integration-a study ${ }^{1}$ carried out into the conditions of transferability of scenario from training to use of IT and a study into the elaboration of 'scenarios in use' (Vivet, 1990)-suggests that this use in training is perhaps necessary but is certainly not sufficient on its own. 


\section{SOME CONDITIONS OF ACTUAL INTEGRATION}

\section{The teacher's rapport with IT}

The teacher in an IT environment must have a good knowledge and a fairly good mastery of IT. While teachers must also accept the fact that they will not be completely masters of all aspects, there are many teachers who cannot bring themselves to use certain software because they have not yet mastered all aspects of the situation which they propose to their pupils. These teachers have a certain difficulty in perceiving what their role as teacher could be, i.e., their role being that of bringing the necessary mathematical knowledge to the exploitation and interpretation of the results obtained, with the pupils in control of the exploration of the proposed situation-often beyond what the teacher would have foreseen even if they had full mastery of all aspects of the software.

Mastery of an environment represents an important investment. Certain people hesitate to make that investment because they do not perceive $a$ priori how they can act in a way to satisfy the opportunities and constraints of the environment across the wide range of programmes which they are responsible for putting into practice.

\section{Frames of reference for teachers}

To administer a learning programme, in class with or without software, the teacher must have a good anticipation of what can be achieved with a group of pupils. If the teacher's expectations for a given learning programme are too far removed from what actually happens, it becomes difficult to apply the necessary discipline in order for this learning programme to function.

In order to be able to organise a learning programme effectively, the teacher who uses software in class must have some background knowledge of what can generally be produced. For a number of reasons (material constraints, programming necessities, place in the learning curve) teachers must inevitably adapt the situation to the real conditions in the classroom. How can they achieve this if they do not have enough experience of using the software in question?

\section{Modifications of training}

The use of software such as Cabri-géomètre facilitates in a very concrete way the approach to certain aspects (of geometry) which are not accessible by other means. It is always surprising to learn on a screen that the image of a polygon by a translation of a given vector does not move if the representation of the vector is moved without changing its direction, its length or its sense. We shall see other examples in the proposed scenarios which follow.

Should these deepening explorations, which, in certain cases, can themselves be considered as new fields of study, be written into the programmes? Indeed they are generally implicit in the spirit of the commentaries. But teachers have some difficulty in integrating them into the programme, particularly in the lycée, and 
they may well hesitate to dedicate time to work whose priority is not explicitly recognised and which is not the object of specific evaluation in the course of study and training.

\section{Long-term investment}

The use of Cabri-géomètre software poses no problems with the human computer interface. Pupils learn very quickly to pull down menus and select tools. They recognise quite quickly the numerous icons. On the other hand, it is only after working for quite a long time with the program that pupils, little by little, become aware of the constraints of this dynamic geometry. If, for example, a square should resist being moved, one must carry out a construction based on the characteristic properties of the square. It is therefore necessary to call on the corresponding tools (primitives). This implies an analysis of the situation and a certain anticipation. Such a process cannot be implemented either quickly or easily. It would be a pity to waste too much energy and time for implementation if this process was not to be used often. Thus it is necessary to show how one can integrate the activities of Cabri-géomètre not meticulously but rather in the construction of learning sequences which are deemed to be important.

\section{USING CABRI-GÉOMĖTRE IN MATHEMATICS TEACHER TRAINING.}

An extract from the worksheets given to first year students at IUFM preparing for the competitive examination, Certificate of Aptitude for School Teaching (CAPE), is given in figure 1. As the tasks given in figure 1 show, it is a question of the students using the Cabri-géomètre program to update their knowledge of elementary configurations: the axis and centre of symmetry of a segment, of a triangle, axis of symmetry of a quadrilateral, characteristics of a parallelogram.

\section{(5.) Some properties}

\section{(5.1) Median}

Create a segment $[\mathrm{AB}]$. Draw the median of $[\mathrm{AB}]$.

Create a random point $M$. Draw the segments [MA] and [MB]. Measure them.

What do you notice about the measurements of [MA] and [MB] when you move the point $M$ ?

Create a point $\mathrm{N}$ on the median. Draw, then measure the segments $[\mathrm{NA}]$ and $[\mathrm{NB}]$. What do you notice if you move the point $N$ ?

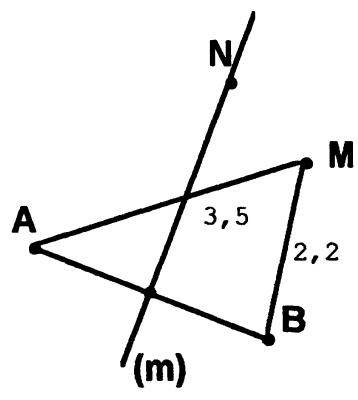




\section{(5.2) Orthogonal symmetry}

Create a straight line (d) and a segment [AB].

Construct the symmetrical figures $A^{\prime}$ and $B^{\prime}$ from $A$ and $B$ around (d).

Mark a point $\mathrm{M}$ on $[\mathrm{AB}]$.

Construct the symmetrical figure $M^{\prime}$ from $M$ around (d).

Move the point $M$ on $[\mathrm{AB}]$ and observe the displacement of $\mathbf{M}^{\prime}$

(d)

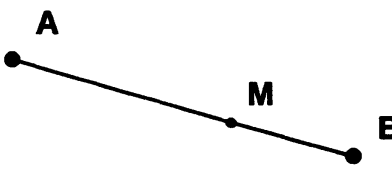

(5.3) Axis of symmetry $\longrightarrow$ of a segment Create a segment $[A B]$ and a straight line (d).

Construct the symmetrical figure $\left[\mathrm{A}^{\prime} \mathrm{B}^{\prime}\right]$ from $[\mathrm{AB}]$ around $\mathrm{d}$.

Move the straight line (d) or the segment $[\mathrm{AB}]$ in such a way that $[\mathrm{AB}]$ and its symmetrical figure coincide. Is there one or more than one solution?

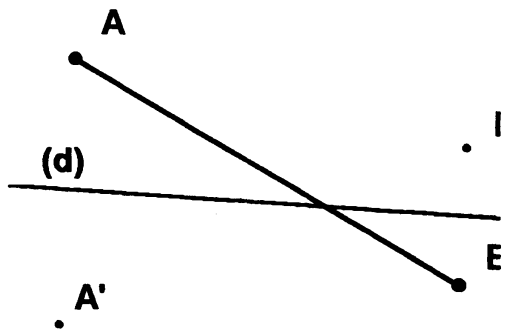

\section{- of a triangle}

From a straight line (d) and a triangle $\mathrm{ABC}$ construct the symmetrical figure of a triangle around the straight line $d$.

Try to modify the position of the straight line (d) so that the triangle and its symmetrical figure coincide.

Can they be made to coincide if the shape of the triangle is changed?

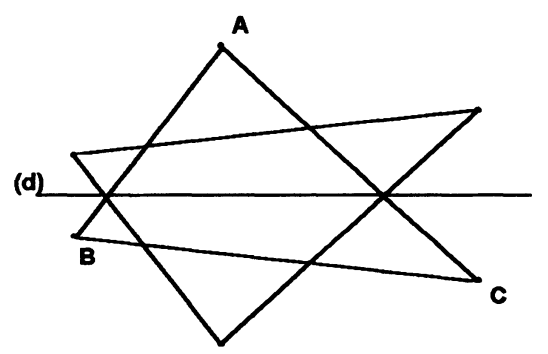

\section{(5.4) Centre of symmetry of a quadrilateral} Create a point $O$ and a quadrilateral $A B C D$.

Construct the symmetrical figure of the quadrilateral $A B C D$ around the point $O$.

Try to move the point $O$ until $A B C D$ coincides with its symmetrical figure. Is this possible?

And if you try to modify the shape of the quadrilateral $\mathrm{ABCD}$ ?

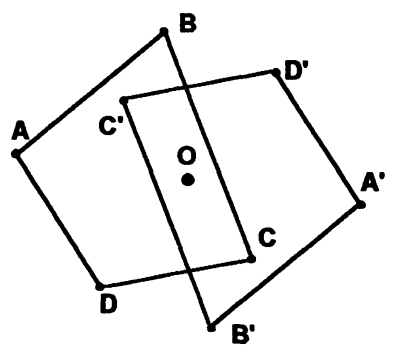

Figure 1 Geometry worksheet 
In moving the basic points of a given figure, the users find themselves faced with a reaction of the system which can be interpreted using previous knowledge. This situation seems interesting to exploit at this level because it permits an updating of knowledge which is not a simple 'revision' in the scholastic sense of the term, but which itself gives rise to new perspectives.

But this type of work has its limits. It necessitates entering into the spirit of the software. In addition, those students with minimal or even no experience in using IT can find even just using a mouse, for example, awkward and hence may well lose sight of the analysis of the situation (and will need to return to the tasks again). Those students with considerable experience of geometry are not likely to return to this level of activity.

\section{INTRODUCTION TO CABRI-GÉOMÈTRE FUNCTIONS AND THEIR USE IN THE CLASSROOM}

Mathematics graduates of the competitive recruitment who are now doing a one year training course at IUFM for two thirds of their time and who have responsibility for teaching a class for one third of their time are given a presentation of Cabri-géometre and of the geometry which can be used with this software. The presentation consists of three sections:

- Section 1: First approach and exploration of certain commands (1 hour).

- Section 2: Appraisal of the first approach; some elements of geometry which can be done using Cabri-géomètre; introduction (with the aid of an overhead projector) to some new functions, such as macro-construction (1 hour).

- Section 3: Presentation of various uses that can be made (of the above) in teaching at secondary level ( 3 hours) - see figure 2.

This presentation is followed by an appraisal which allows for reflection and discussion about the teaching of geometry in secondary schools and of the use of Cabri-géomètre software with the pupils.

There are appended sheets for each activity which provide the basis for an appraisal; trainee teacher must note their objectives, the way they expect to use the system in class and the way pupils are expected to use it. As the activity progresses, each trainee must therefore pass from a situation like that of being a pupil in a secondary school to one of teaching mathematics, envisaging the use of Cabri with the pupils, necessitating therefore specific reflection and an overview of the actions required. 
For each of the following activities, indicate on the appended sheets:

- the geometric objectives that you are assigning them

- the way it will be used in class and what you expect the pupils to do

(3.1) In order to visualise a property

THE ANGLES OF A TRIANGLE

Draw a triangle $A B C$. Draw a line (p) parallel to the side $\mathrm{BC}$ which passes through A. Mark the angles of the triangle and those determined by (p) and the sides $\mathrm{AB}$ and $\mathrm{AC}$. Measure them. Move the apex of the triangle and observe the changes in measurement of the angles.

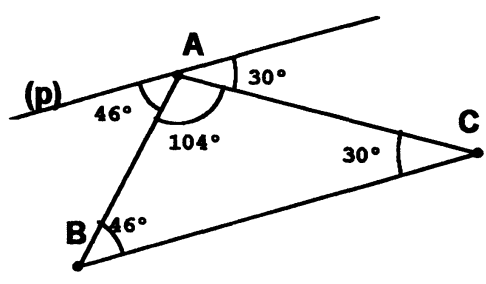

(3.2) Setting some problems of construction

(3.2.1) Two aperes and the centre of gravity

Create two points $A$ and $B$. Create a point $G$.

Construct a triangle $\mathrm{ABC}$ of which the centre of gravity is $\mathrm{G}$ using only the commands featured in the following menus:
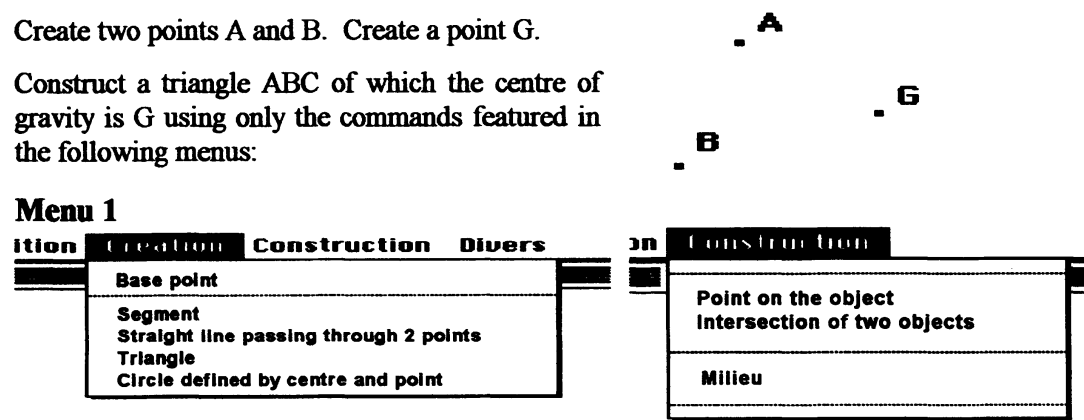

Figure 2 An extract from Section 3 of the presentation of Cabri-Géomètre.

\section{THE INTEGRATION OF IT TOOLS THROUGH DIRECTLY USABLE SCENARIOS IN TEACHER TRAINING}

Work on usable scenarios has been done under the umbrella of a research programme supported by the Rhone-Alps region and by the Institut National de Recherche Pédagogique (INRP) launched by the Environnement Informatique et Apprentissage Humain (EIAH) team of the Leibniz Laboratory at IMAG. ${ }^{2}$ An illustrative example of this work is the scenario for introducing the notion of transformation to students aged 15-16. 
The idea of geometrical transformation occupies an important place in the teaching of mathematics in France. It is begun at secondary school as transformations which operate on figures (the 'configuration' concept) but must be used at the grammar school (lycée) as a more formal mathematical transformation, i.e., the 'functional' concept-transformation of the plane onto itself, an idea very difficult for pupils to conceptualise.

The scenario will makes explicit the ideas that:

“... these transformations need not be presented as the transformation of a plane onto itself. According to the case, they will appear in the actions on the figures or as leaving a figure unchanged" (Pupils aged 13-14)

"In the spirit of the school programmes, one will first make transformations to the figures, then one will extract the essential idea that a transformation associates at all points of the plane figure, with a predetermined point on the plane. (Pupils aged 15-16)

The transition from secondary school level with 'transformation of the figures' to grammar school level with 'new applications' is not a natural one. On the contrary it marks a break because the two aspects bring into play different concepts of the view of the plane. The 'essential idea' underlined in the programme implies a homogeneous concept of the plane which is absent at secondary school level. The evaluations at the end of the fifth form state that 'the more mathematically focused aspect is not mastered by the pupils'.

The Cabri-géomètre program permits any transformation to be represented, like a black box (Charrière, 1996). This results in a particular construction obtained from the designation of a certain number of elements (specified in the on-line help) without one having to be familiar with the method of construction or the subsequent phenomena which might occur. The analysis of the effects of changing the basic elements permits the user to reconstitute the black box which has been postulated.

Thus one can work very quickly with the transformations without preserving the measurements, for example, the oblique symmetry for which the image of a circle is not usually a circle. It is even very easy to work on the transformation of a right-angled cone to illustrate the fact that a transformation does not necessarily preserve the alignments.

Using a homothetic transformation one can, for example, implement the construction of the image of a quadrilateral. The 'homothétie' tool ('dilation' on the TI-92) of the software permits instantaneous production of related; the user need only designate a number (the relationship), a point (the centre) and obviously the figure whose image is wanted. By observing the movement of the basic elements one can show, in particular, the fact that this transformation preserves the forms. The tool Pointer allows instantaneous transformations in all constructions realised in the case of displacement of the centre, in the case of modification of the relationship of the homothétie, this provides a range of 
deformations of the basic figures - triangle, polygon, circle or, more simply, segment, straight line, half line, etc. The resulting screen animation enables the pupil to acquire, without a great investment, a global visualisation of homothétie: its action on everyday figures and its essential properties are conjectured as a result of numerous attempts which one can produce on the screen within a short space of time. One can easily observe the alignment of a point, of its image and of the centre. Modifications to the value of the relationship oblige one to interpret the immediate adjustments made by the system. The calculator, which is available within the program, permits the relationship to be determined on the basis of the dimensions of the given elements and those of their images.

This approach with Cabri-géomètre software permits work on the mathematical aspects of transformation. If one creates a point on a common figure (in this case it is 'tied' to the figure and cannot be displaced outside the figure), then by transforming its image it is possible to follow the displacements which result from moving the point in going outside the figure to which it belongs, for example, the image of the given figure is obtained, thanks to the software. This activity permits a close link to be established between the global aspect of a transformation applied to common figures and the point aspect of the application of the transformation of the plane onto itself within the specified domain (the display).

\section{STIMULATING THE CONSIDERATION OF SOFTWARE TOOLS: CALCULATORS AND THE TI-92}

Having been admitted into the optional CAPES (Certificat d'Aptitude du Professorat et de l'Enseignement Secondaire) 12 hour module in theoretical proof, trainee teachers in their second year at IUFM have been able to familiarise themselves with the use of certain functions of the TI-92, which also possesses a version of Cabri II.

Thus the work on many of the activities and current worksheets are now possible within this new hardware and software environment. Advantages of this new technology are those of portability and the potential for personal exploration outside the computing laboratory.

In addition, the IUFM programme has begun to address a number of different aspects in the use of the technology by developing scenarios for the teaching of mathematics based on, for example:

- the existence of two levels in the treatment of numbers, integer arithmetic and decimal approximations as found in normal scientific calculators;

- operations utilising the graphics representation of objects, e.g., a square, based on the functional definitions required to produce the objects; and

- operating on vectors in an approach involving the sectioning of the plane using equations of straight lines. 
Here again, the essence of the problems posed, i.e., the scenarios, are those which might be considered in the school mathematics classroom, and as such represent the real potential for the integration of the hardware and software tools in teaching and learning.

\section{Notes}

1 "Les conditions de reproductibilité et de transfert d'innovations: le cas des environnements informatiques pour la formation", menée conjointement par des membres de l'équipe ELAH du laboratoire Leibniz de l'MMAG, de l'TUFM de Grenoble et de Lyon, de l'IREM de Grenoble et de Lyon et soutenue par l'INRP: "The conditions of reproducibility and of transfer of innovations: the case for IT environments in training" carried out jointly by members of the EIAH team of IMAG's Leibniz laboratory, of IUFM of Grenoble and of Lyon, of IREM of Grenoble and Lyon and sustained by INRP

2 This programme, managed by $\mathrm{C}$. Laborde, includes: researchers into teaching, $\mathrm{N}$. Balacheff, B. Capponi and C. Laborde; researchers into IT and mathematics C. Payan and L. Trilling; grammar school (lycée) teachers M. Arragon (Physical Sciences) and A. Sanfort (Mathematics); a lecturer in teacher training at IUFM, P. Clarou.

\section{REFERENCE}

Charrière, P-M. (1996). Taming geometry with Cabri-géomètre. Monograph issued by the CIP, Geneva.

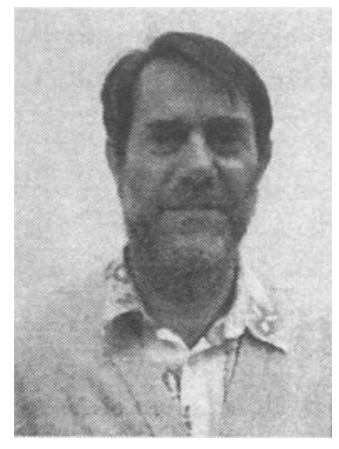

Philippe Clarou is currently a mathematics teacher both in secondary school and at the University Institute for Teacher Education in Grenoble where he is training future teachers for primary and secondary schools in the field of mathematics and mathematics education. He has been a mathematics teacher in secondary school for 20 years and has been actively involved in the work of the IREMs (Institutes for Research in Mathematics Education) since their inception. He also worked for three years at the Centre for Informatics and Pedagogical Applications at the scientific university of Grenoble before the creation of the Institute for Teacher Education. Philippe Clarou is currently a member of a research project, about the integration of ICT in mathematics teaching, supported by the National Institute for Pedagogical Research. As part of this research, every student in his class (16-17 year olds) has been given a TI-92 for the academic year. 